\title{
Providing Useful Knowledge, Becoming Embedded: Issues and Tensions as a Racial Justice Ally
}

\author{
Pamela Oliver \\ University of Wisconsin \\ CBSM Conference August 2011
}

This informal essay tells stories and provides reflections based on my experiences working with groups around racial disparities in imprisonment. I discuss three topics: (1) what kinds of knowledge are useful and how sociologists can contribute to producing useful knowledge; (2) the general problem of class and expertise and the interplay of race and class hierarchies in creating knowledge within movements with special attention to the role of sociologists; (3) the generic problem of opportunism and conflicts of interest and perspective and how sociologists fit into these problems. In developing these arguments I draw on longstanding discussions of tensions and conflicts between beneficiary constituents and conscience constituents. I also advance the concept of an activist professional, a person whose activism is closely related to or intertwined with their job, and make the point that activist professionals often experience tensions and conflicts of interest between advancing the movement and advancing (or at least not jeopardizing) their careers. I argue that academics in movements are typically conscience constituents and activist professionals and that academics who seek to work with and provide useful knowledge to movements should be aware of these tensions and conflicts.

The formal distinction between beneficiary and conscience constituents was (so far as I know) first advanced in the social movement literature by McCarthy and Zald. The term "beneficiary constituency" refers to the people who will benefit directly from the movement in question. Drawing on Morris and Braine (and others before and after them), I believe it is important to distinguish between movements like peace and environmentalism, in which everyone is a beneficiary, and movements by oppressed or disadvantaged people in which the beneficiaries are oppressed or disadvantaged. Conscience 
constituents are people who support a movement by oppressed or disadvantaged people who, themselves, are not members of that oppressed or disadvantaged group.

The problematic of conscience constituents or allies in the movements of the oppressed was central to movement politics between 1965 and 1975. As the Black Movement shifted from Civil Rights to Black Power, conflicts between Blacks and Whites within the movement, especially within SNCC, led to a rise in separatism and an awareness of the problematic dynamics when one group of people tried to help another group. White leftists were instructed to "go organize your own communities." A little later, the women's movement entered a separatist phase as many women felt the need to organize apart from men. These movement experiences fed into the conceptual distinction between beneficiary and conscience constituents and a recognition that there were likely to be conflicts in organizations that tried to house both kinds of constituents.

The dynamics that animate most of my talk assume that academics are conscience constituents working on behalf of a group they are not a member of. I am a conscience constituent in the racial disparities issue, and I am acutely aware that my race and class position influence everything I do. When I make general statements about the position and role of academics as relatively privileged movement participants, I'm making the assumption that we are operating as conscience constituents. Academics who are, themselves, members of an oppressed group will not find all my remarks to be appropriate to their situation, although my reflections on the cross-cutting pressures faced by Black professionals may be relevant.

The second concept I use is the idea of an activist professional. The term professional activist typically denotes someone who is paid to be an activist. I'm going to use the term activist professional more broadly to encompass not only people who are paid to be activists, but anyone whose activism and job overlap. In doing so, I want to extend thinking about the issues of professionalization in social 
movements. McCarthy and Zald not only recognized that professional social movements were in ascendency, but that there were inherent conflicts in organizations that tried to blend professional activists and beneficiary constituents. Subsequent research showed that some movements were carried, not by people who were paid to be activists, but by activist members of professions. This is especially common in movements on behalf of people who cannot easily act for themselves, such as mentally ill and physically disabled people. For example, much of the disability rights movement activism was carried by professionals serving the disabled. In these movements, too, scholars recognized the potential conflicts between the beneficiaries of the movement and the non-beneficiary constituents.

The important insight about activist professionals is that they care about the movement but they also care about keeping their job and advancing in their career. This would apply to anyone who has an employment or career stake in the movement, including politicians. Academics in movement are also activist professionals if the research they do for or about the movement is also part of what they are counting as publications or professional activities. All activist professionals face potential conflicts between their career interests and the collective interests of the movement. In addition, activists professionals, like all other activists, inevitably see issues through a lens shaped by their personal and professional position and experiences.

In discussing the role of activist professionals I also need to be clear how I'm viewing social movements. The traditional image of the social movement centers on protest. But the reality is that the totality of actions of people promoting or resisting social change is typically carried out by a fluid and amorphous collection of people in different kinds of organizations doing different kinds of things all moving toward the same general goal. No movement ever uses only protest to achieve its ends, and some don't use protest much at all. Nor is it correct to think of the state and the movement as separate and non-overlapping. In even nominally democratic states, very few groups are totally outside the orbit 
of state power. Instead, most movements, even movements by oppressed people, have allies or even core leaders within the state, as elected representatives or as agency bureaucrats. In fact, as movements progress, one of the things they win is pieces of the state. This does not mean that everyone is equal. Your group can have representation in the state and still be oppressed. But it does mean that the interplay between state and non-state actors is part of the totality of a social movement.

\section{My work}

My comments today are based on my informal observations and reflections while doing public work, not on systematic observation. Some of my reflections are based on my experiences as a participant in mixed-race community groups in the 1970 s. Most are based on my more recent work. I have spent much of my time in the past 10 years doing public sociology work in Wisconsin around racial disparities in imprisonment and criminal justice. Since 2000, I have given over 100 Power Point lectures to a wide variety of audiences demonstrating the patterns of racial disparities in imprisonment in the US and Wisconsin. These slides have an impact and tell a story about racial dynamics in the US that cannot easily be conveyed in words. They show not only that there is a racial disparity, but that it increased in the last quarter of the $20^{\text {th }}$ Century, that the drug war was a major source of the disparity, and that Wisconsin even worse than the rest of the country. After seeing the presentation, audience members agree the problem is serious and that some of their ideas don=t fit the data, even as they have different ideas about solutions. My slides are posted on my web site ${ }^{1}$ and have been downloaded by and distributed to people I have never met; my work is regularly cited and discussed within criminal justice circles in Wisconsin. I have frequent media contact within Wisconsin and am often quoted as an expert about these issues.

1 http://www.ssc.wisc.edu/\%7Eoliver/home.htm follow links to the "racial disparity" section 
I have also worked with several local groups around these issues. In 2000, I joined the board of an advocacy group Money, Education and Prisons (MEP). My visibility on the racial disparities issue led to my being asked in 2003 to join the advisory board for Dane County's federally-funded Disproportionate Minority Contact (DMC) project in juvenile justice. In April of 2007, this same visibility led to my appointment to the Governor=s Commission to Reduce Racial Disparities in Criminal Justice. In 2008-9 I served on Dane County's Task Force on Racial disparities. Each of these experiences involved complex, sometimes very gratifying and sometimes painful and acrimonious, racial and class dynamics that have fed into my perceptions of social justice work and the role of academics in it.

As my remarks will center on the importance of bringing a critical sociological lens to one's own particular social location in a social movement, let me sketch my own position. I initially got into this work "as a person" not "as a sociologist." I was pulled into racial disparities work by the organizing efforts of local community activists and by my desire to get involved in some sort of social justice work, not by sociology. I first became involved in 1999 after attending a large conference called "Money, Education and Prisons," put on by a local advocacy group that was linked to Madison-area Urban Ministry (MUM), a progressive group whose motto is "planting the seeds of social change." MUM decided to run a forum series about prison issues and I volunteered to be on the planning team for that forum series. As part of that, I volunteered to acquire and present information on patterns of imprisonment. I argued that people would want to know what people were in prison for and other information about the patterns of imprisonment. Although this did not necessarily seem the most important thing to everyone else, they thought it would be an appropriate component of the forums. Thus I began as a volunteer among volunteers. I offered my sociological skills the way other people offered to do publicity or to make dinner arrangements. But I was not the leader, I was not the expert. I was joining a movement started by others and trying to do my part. 
In particular, I am not a criminologist and when I started I had very little knowledge to offer people. Instead through a combination of skill and luck, I gradually accumulated knowledge. After doing some preliminary work using National Corrections Reporting Program data, I lucked into a copy of the data from Wisconsin's Department of Corrections and, with the aid of a grad student who was also volunteering his time, processed the data and turned it into graphs showing trends in prison admissions by race, offense and county. Nobody had ever done this analysis. The information was powerful, and presenting it had an impact. It told people things they did not know and forced people to confront the problem. It was lucking into this data after l'd started as a volunteer that turned me into an "expert."

The racial disparity issue was slow to take off among activists. Local prison activists, mostly White but even some Blacks, thought they already knew what they needed to know about race, and feared that stressing the racial dimension would just feed into people's prejudices about imprisonment. They were more concerned about truth in sentencing and the supermax prison. Initially, I got much more attention and support from social scientists than from activists on the racial disparity issue. Wisconsin's Institute for Research on Poverty provided me with a research assistant for several years, and the National Science Foundation provided a small grant to try to develop what I call the "sociology" part of the project comparing states. My larger more grandiose grant applications were rejected by several agencies because they were naive and ill-focused. This professional project has been slow to pay off precisely because I lacked a strong professional background in criminology and spent most of my time doing the applied public work. Nevertheless, the fact that I already had tenure at a major research university made it possible for me to do this work. It gave me substantial resources for the work and it gave me the job security to permit risk-taking and the diversion of efforts into an ill-defined path with no clear professional payoff. 


\section{Useful knowledge}

The first question about useful knowledge is what kind of knowledge a movement needs. There seem to be three ways in which knowledge is useful to a movement: informing the movement itself about the specifics of the problem or issue, informing people outside the movement about the problem or issue in the hopes of attract support or allies, and helping a movement plan its strategy or tactics. I will focus primarily on the first two kinds of knowledge use.

\section{Knowledge about the problem or issue}

Academic research can often help people see what the problem is and where it is coming from and itself can be a weapon, tool, or resource for promoting change. Years ago, Gay Seidman told me to remember that most social movements don't need academic help in techniques of organizing or mobilizing, they need academic help in gathering and presenting information about the issue itself: Information about potential threats like toxic dumps or dams or watershed pollution. Or information to document patterns of inequality or unfairness in how institutions operate. Or they need information about the kinds of solutions to problems that have worked elsewhere. Or they need help organizing and conveying information about the consequences of social problems and policies in a way that will draw allies to their cause.

As a scholar of social movements, I think there are tons of fascinating things to study and theorize about in social movements. But my expertise in social movements was of almost no value in working on the racial disparity issue. (What my social movement expertise does give is some analytic purchase on the problems of working with other people in the movement, which I will discuss in a few minutes.) I have made many mistakes and been slow to grasp some key issues precisely because I do not have a background in criminology or criminal justice or legal studies. I would say that anyone who wants to be useful to a movement should do what they can to become an academic expert in the thing itself, the 
issue itself, in addition to whatever expertise you have in social movements. People who are narrowly trained as social movement scholars may find that their academic expertise is not particularly useful to a movement

That said, even though I lacked expertise in criminal justice issues, my general skills as an academic were of great value when I became concerned about racial disparities. The most important academic skills are digging out information and knowing where to look for information, performing quantitative analysis to identify trends and connections, and writing and presenting information in a clear, lively and accessible way. Although our journal publications are often inaccessible to the general public, our teaching ought not to be, and writing for the public is pretty much the same skill as writing a good lecture for an undergraduate class. As academics we also often have access to sources of information through our university connections that are not freely available to the general public. I'm thinking here of access to journals and data archives like the ICPSR.

My contribution has been to get information that is officially public data but not readily accessible, to do a detailed statistical analysis, and to present trends and patterns in graphs and a lecture style that ordinary people can understand. Apart from PowerPoint presentations, I have self-published graphs, PDF copies of reports, and PowerPoint presentations on my web page that have been downloaded and passed around and incorporated into lectures and reports by people I don't even know. Information I have generated is often used by others without citation. But if your goal is social change and not selfpromotion, your emphasis is on getting the information out, not on restricting access so you can get credit. l'll come back to this point later.

For knowledge to be truly useful it must be correct, insightful, and accessibly presented. I believe that the academic standard of getting it right is central for knowledge to be useful. Wrong findings in obscure academic journals don't hurt anyone, but wrong information fed into social policy can have 
deadly consequences. What gets complicated is that the "correct" findings are often a result of complex technical analyses controlling for things like extraneous variables and endogeneity. There is also the deep matter of theoretical insight that tells you what things to control for and how to interpret descriptive patterns. We know that academic researchers working carefully and honestly may still reach different conclusions about tangled causal relations. Academics get to write articles explaining how everything is intertwined, but policy makers and activists have to sort out causal relations if they want to know how to fix things.

Activists and policy makers often are impatient with complexity and just want a 25 -word bottom line. Making the complex accessible is hard. In the disparities issue, for example, people start with a simplistic dichotomy: either it is all due to discrimination, or it is all due to racial differences in the rate of committing crimes. But it just isn't that simple. Discrimination itself leads people to commit more crime, and a lot of the disparity arises from institutional practices and patterns, not biased decisions by single individuals. And actual discrimination often leads no trace in public records. Three examples of what I'm talking about. First, a growing body of research shows that much of the disparity is placebased, not person-based. Different places are policed differently. Specifically, the places where a lot of Blacks live tend to be policed differently from the places that are overwhelmingly White. Frequently it is entirely different law enforcement agencies policing different places. Even if each agency is entirely nondiscriminatory in its own practices, the agency differences can produce huge disparities. This feeds into the second example, the impact of prior record. Everybody in the criminal justice system believes in the principle that you should be treated worse for any given offense if you have prior offenses in your record. But place-based differences in policing mean that young people in some places are much more likely to have prior records than in other places, even if their actual behavior has been the same. Finally, actual discrimination rarely leaves a trace in the records. It arises from driving while Black and walking while Black stops for which no records are kept, or in the ways behavior is described in reports. It takes a 
lot of sociological insight to consider these kinds of factors and to think of ways to try to measure their impact.

This is why accessibility is hard. Explaining complicated issues like this is extremely difficult. I must have said to the same group of people the same things dozens of times: discrimination versus differential crime is a false dichotomy, we already know the answer that it is some of each. The Black incarceration rate is a different measure with different things that cause it than the racial disparity index. You can reduce the Black rate with policies that also reduce the White rate and can thus dramatically reduce Black imprisonment while increasing the disparity ratio. The White rate is in the denominator of the disparity ratio: if you want to reduce the disparity, the most efficient thing to do is to lock up more White people, but that will not get Black people out of prison. Prior record is not a transparent measure of how bad someone is: it also encodes jurisdictional differences in arrest and charging policies. Discrimination often happens through unconscious perceptual bias, not intentional differential treatment. If you have had the teaching experience of explaining things as clearly as you can and still have students misunderstand the point, you will recognize the feeling. Except these are not students whom you can justifiably patronize. These are working professionals and committed community activists who know a heck of a lot more than you do about other parts of the problem.

The things that make our teaching better also make our accessibility better. I have influence because I figured out how to make graphs that could tell the data story visually. Graphs also can convey causal relationships to help people see how different parts of a problem are related. Beyond that, you just need to work on writing and speaking clearly, concisely and with expression.

\section{Knowledge to draw allies}

Another kind of "knowledge" that academics contribute is not to inform the beneficiary constituents at all, but rather to try to attract conscience constituents by bringing attention to their situation. Much 
of the same information that informs the movement about the problem may also be used to draw allies. This is actually what most of my work does. I have spoken to a fair number of Black prisoners and exprisoners and have learned from them. Some Black community members say Black people should see my presentation so they know what they are up against. But mostly Black people feel they already know what the problem is and don't need any more information about it, they just need somebody to do something about it. The primary impact of my work has been to draw White attention to the problem. To the extent that Black people appreciate what I do, it is for being a White person willing to talk about the issue and put a White face on the issue to try to bring it legitimacy among Whites.

In addition to my kind of work-generating statistics and talking about them-there is a genre of qualitative studies of stigmatized or oppressed people that potentially play a similar role, in drawing outsiders' attention to the struggles and needs of an oppressed population or to revealing patterns of inequality or social harms.

Presenting information about social problems to non-movement members to try to gain their support is often important work for a conscience constituent to be doing, but it inevitably raises tensions. There is an inherent power dynamic when you use your position of privilege to call attention to the problems of an oppressed group. People quite justifiably want to know why it takes some high status person saying something just to get it listened to. Politically aware and conscious members of an oppressed group will often resent a conscience constituent like me precisely for this reason. In addition, it is very easy unintentionally to disrespect or hurt people when you are trying to help them. As you try to explain or convey how an issue looks from somebody else's point of view or how their lives are impacted by a bad social policy, you inevitably start speaking about people as objects. Nobody is comfortable being described in the third person, and no matter how much you try to understand, if you are not living a life, you will never get it quite right when you try to explain it. 


\section{Tactical and strategic knowledge}

For the sake of completeness I will mention that the other kind of knowledge that may be helpful to movements is knowledge about how to increase power or influence: tactical and strategic knowledge. I think this is the kind of knowledge that social movements scholars might have, although in practice l've rarely seen academics contribute much to this knowledge. It seems like social movements theory is more about translating tactical and strategic principles from field experience into academic knowledge than the other way around. Good tactics and strategy are never about invariant textbook principles and are always fluid and contingent, based on analyzing a specific situation and seeing a way to create an advantage with the tools at hand.

My general sociological knowledge about how movements and organizations and systems typically work has given me some sense of perspective as I work with groups and has, at times, allowed me to make suggestions or provide a perspective that has helped others. I'm particularly good at providing a sense of perspective in the face of setbacks. But I have never felt that my academic credentials gave me any particular tactical or strategic gifts. Some academics may happen to have those talents, but I would offer that they have the talents "as activists" not "as sociologists." Perhaps others can address that issue later.

\section{Power hierarchies and cultural conflicts in the creation and transmission of knowledge}

Knowledge-creation is a big part of social movements. Social movements change how people think about things and make them aware of the consequences of policies and actions. Intellectuals have always played a role in the knowledge-production part of social movements. At the same time, part of what movements by and for the oppressed are about is lifting up knowledge from the perspective of the oppressed. But the very fact of oppression and hierarchies of privilege can hinder this. Hierarchies of 
privilege also create cultural divides that lead to misunderstanding and miscommunication. Whatever we sociologists do about producing useful knowledge we should try to contribute to expanding the voices that are heard.

If academics are going to be useful to movements, we have to be willing to be humble and recognize the limits of our knowledge. The people closest to the problem often have knowledge that is unavailable to the people who are more distant from it. For example, offenders and ex-offenders and their families know a lot about the day-to-day dynamics of how offenders are treated and what factors get them into trouble or keep them out of trouble. Low income people know a lot about what happens to you when you cannot pay the rent. Police know a lot about the realities of policing from a police point of view, and Black youths know a lot about the realities of policing from a Black youth point of view. The knowledge that academics bring to the table is usually the ability to put these daily experiences into a broader perspective, but the academic typically has little or no day to day knowledge. If you are really trying to change something, you have to have an accurate understanding of how the whole system works, so ideally you want knowledge from as many different points of view as possible.

Apart from giving speeches to whomever is willing to listen, I have spent a great deal of time listening to people, both the audiences for my talks and in attending meetings of advocacy groups and quasi-governmental commissions and task forces. Most of my audiences have been White, but a few times I have had the privilege to speak to a predominantly-Black audience, and have always learned a great deal from the experience. The advocacy group started as mixed-race but became Whitedominated over time although with the periodic involvement of Black activists; at times one or more exoffenders were part of the group. The Advisory Board on juvenile justice, the Governor's Commission and the Dane County Task Force were all consistently mixed-race with strong leadership from Black activist professionals as well as ongoing active participation from White activist professionals and less 
consistent participation from offenders and ex-offenders. I have been only tangentially involved with the circle of groups around Madison Urban Ministry; its leadership is White but it maintains significant Black participation and leadership in its board and programming. Most of my speech-giving has been to predominantly White audiences, but I have occasionally been invited to speak to predominantly-Black audiences. I have spoken both to the general public and to audiences of criminal justice professionals, including correctional workers, judges, defense attorneys, and police.

The most important things I have learned in all this activity is that there is a lot of knowledge out there that some people have and others do not and that there are tremendous divides among people in how they perceive the system that are tied to their experiences and knowledge. Whatever we sociologists do about communicating knowledge that we have generated to others, we also need to try to help bridge communication chasms, to listen to other people about what they know and then do what we can to help pass that information along to people who don't know it. This involves seeing oneself not as an expert but as a member of a community and a network node. But it is a mistake ever to think that you have transcended your own race/class/gender position.

Offenders and low income people have a lot of the practical knowledge about how people got into trouble and how the tangle of consequences of poverty and institutional rules created challenges for people who were trying to get off the criminal path. They also had a lot of direct experience with being treated rudely or stopped and asked to account for themselves when going about their law-abiding business. Every time offenders or low income people spoke, they provided information that was often shocking for the more privileged group members. (And I include myself among them.) But it was not easy for them to be heard and have their voices incorporated. Both the Governor's Commission and the Dane County task force held hearings designed to solicit experiences and information from "the community." The summary of this testimony went into an appendix of the Governor's Commission 
report without much notice or controversy, partly because it also included testimony from officials and partly because it was buried in an appendix. But the discussion on the Task Force became quite acrimonious as people disagreed about what was legitimate testimony and whether it was fair to summarize citizen complaints because they were one-sided, unverified or a biased sample that was not representative of everyone's opinion. The police representative objected to one Latino's story of being stopped often after the big immigration rally even though he is carefully law-abiding and had never been stopped before. "It makes us look bad," he said. (Interestingly, the police department's own internal research had identified a "renegade" officer who was, in fact, stopping Latinos at extraordinarily high rates, and the man's story was quite consistent with this research finding.) There were even some objections to including the statement "there is widespread perception of bias" in the report on the grounds that it wasn't based on a scientific sample of the community, even though this perception was reason the task force even existed! These debates were ultimately resolved after a Hispanic man pled for the inclusion of people's voices in the report by including the summary after excising a few of the more inflammatory statements and adding a statement about unrepresentativeness.

There were also barriers that arose from racial-cultural difference in the rules for expressing disagreement and talking about race. The dominant White culture in the upper Midwest is particularly adverse to the overt public expression of anger or even disagreement-politeness is the norm and passive aggression is the culturally preferred way to express disapproval. Black people are often perceived as angry or hostile by Whites, and Black people who expressed themselves in aggressive ways were often not "heard" but instead were responded to with withdrawal or offense. Nobody ever called any other person in the room racist at any meeting I was at, but any mention of racism or discrimination even referring to institutional practices or the seemingly-egregious behavior of some other person outside the room was likely to trigger a negative reaction. Mention of generic complaints about racial bias in policing, prosecution, or defense frequently evoked negative responses, even though addressing 
such complaints was the stated purpose of the task force and every member of the task force agreed in principle that discrimination existed. Even the friendly and mild-mannered Black ex-offender who ran a reentry project and normally got along with everyone evoked a negative response when he used the word "racist" to complain about the all-White construction crews in public works. The context was job opportunities for ex-felons, there had already been general discussion of the problem of employment discrimination, and his point was clearly that construction firms getting public money should hire Blacks and returned prisoners, but using the word "racist' still led some White participants to claim that they could not be expected to sit at the same table if people were going to be called racist.

Professionals in the system often had radically different perceptions of reality depending on where they worked. As one example, the district attorney, many judges and many supervisors in corrections insisted that parole revocations could not be capricious or arbitrary because all revocations required a court hearing that had to persuade a judge that a revocation was appropriate, while a court commissioner and public defenders told me that many parolees are persuaded to waive their hearing by being told that they would be treated better if they did not demand a hearing. I heard stories from many parolees, their families, and people who work in reentry of capricious and arbitrary parole holds and revocations. The empirical question of whether there was a high rate of revocations without hearings could not be adjudicated because the Department of Corrections kept no systematic data on the matter. Additionally, people can be incarcerated on probation or parole holds and the probation/parole officer's say-so while someone investigates whether a revocation is warranted, effectively administering punishment before a finding of guilt. Holds are typically for a few days or weeks but can last for months and even years. But from some professionals' perspectives, these facts were simply invisible.

People who are not close to the problem pass all kinds of seemingly-benign laws without recognizing their consequences. There were a whole variety of ways in which laws and regulations acted 
in ways that effectively incarcerated people for not having money. One was making incarceration a penalty for non-payment of child support and another was a provision that leaves the child-support meter ticking while an offender is incarcerated, thus leading to back child support bills that cannot possibly be paid by a low income person. Incarceration for non-payment was particularly likely for people on correctional supervision as it could be generated by an administrative hold. Offenders reported being incarcerated for non-payment even though the probation/parole officer knew they'd been laid off from their jobs. Or, in reverse causation, incarcerating an offender for non-payment would lead him to lose his job, thus triggering further non-payment and incarceration for either or both of the non-payment and the unemployment (both violations of the conditions of supervision). Another was fines for municipal tickets for things like noise ordinance violations or driving without a license, which led to bench warrants and incarceration when the fines could not be paid.

The driving without a license problem is particularly instructive. A variety of ill-considered laws and regulations have made it very common for low income people to have no valid driver's license in Wisconsin. Some of these include educational deficiencies that prevent people from passing the written test, the legal requirement that people under 18 take a $\$ 400$ driver's education course before being licensed, and automatic driver's license suspension for drug crime and other convictions (including the rule that if you do not have a driver's license when convicted, the suspension is waiting for you when you first apply for a license). The penalty for driving without a license is a combination of a large fine and the inability to get a driver's license until the fine is paid. The inadequate public transportation system makes it very difficult to hold get to and from a job without a driver's license. The consequence is that many people drive without a license and cannot become licensed drivers without paying hundreds or even thousands of dollars in fines-money they do not have-and jumping through a large number of bureaucratic hoops. The further consequence is that people really do end up incarcerated for driving without a license, either by way of a probation or parole revocation for violating a law or by way of a 
bench warrant for the unpaid fines. This driver's license problem is inter-generational. In one family, attempts to have the teenaged child drive legally were thwarted even though they could pay for the driver's education course because the car insurance had to be in the name of an adult with a valid driver's license and no adult in the family had a license. As people became aware of this tangle consequences, even relatively conservative Republicans and state bureaucrats came to agree that the situation was impossible and a bi-partisan reform bill eliminated some of the more egregious problems.

Criminal justice professionals had a lot of practical knowledge about the nuts and bolts of how the various systems work and grounded personal experiences from being out in the neighborhoods. I have talked to police pretty often about their work and have gotten a lot of different views. I've talked to some police who explain why it's impossible to discriminate as a police officer and some former police who quit because they could not tolerate what they saw happening on the streets as people who were doing nothing but walking down the street or sitting on a porch were asked for their ID. I have talked often with Black and Hispanic criminal justice professionals who are simultaneously sure that racism and discrimination in the system are real problems and deeply concerned about the normlessness and anger they see among young Blacks and Hispanics. They feel like they are often expected to act as the frontline social service providers in a larger system that is broken.

The usual simplistic social movement images fall apart around these issues. The people closest to the problem think that the criminal justice system is unfair and racist, but they also think crime is a problem in their communities. There was a spate of murders in Milwaukee in couple of years ago and I was on a panel where I presented statistics about racial disparities in imprisonment and another panelist was a Black woman who was organizing a "stop the murders" campaign and trying to get more police presence in her neighborhood. We talked. She thought I was right about the system being unfair, but also thought you had to crack down on the people doing the murders. I've talked to many Black people 
who are both sure that the police are racist and discriminatory in their practices and think the highest priority is to teach Black kids how to stay out of trouble and avoid escalating encounters with the police. One of the things I have realized is that, as a White person, I tend to think of the main actors as the discriminatory White system. But Black people are more likely to think of themselves as actors and are looking for what they can do to survive and help others survive in the face of oppression.

I have argued elsewhere that mass incarceration has had repressive effects on the capacity of low income Black communities to mobilize politically. Movements on behalf of oppressed people are often carried by conscience constituents because oppressed people are oppressed and oppression makes collective action difficult. The racial disparities movement sits at the overlap among criminal justice reform movements and Black movement organizations. It is primarily professionalized. The core beneficiary constituents of the racial disparities movement are highly stigmatized and disempowered Black people who are in or have been in prison, or who are otherwise in trouble with the criminal justice system. Apart from their stigma, their conditions of supervision typically make it illegal for them to gather to promote disruptive or even peaceful protests in pursuit of improving their position. They are truly oppressed and structurally largely unable to engage in collective action on their own behalf. There are some ex-offenders who are active in prison issues and offenders currently on supervision do have a speakers' bureau and have some voice in some public meetings, but their role is limited. I am even aware of cases in which offenders on parole have been detained in jail on a parole hold when schedule to speak at a public event. Apart from the offenders themselves, the communities from which they come are often highly distressed. I've seen people withdraw from participation because of having to take on responsibilities due to a family member's eviction or job loss. Anyone can be subject to ill health, but the correlations of race and class with health mean that low income Black people are more likely to have to withdraw from participation due to their own ill health or that of a family member. 
Over and above these material constraints on participation, the boundaries of class made it difficult for lower income and professional people to work together. A major axis of conflict on the Task Force was email. Professionals had regular access to email and preferred to schedule meetings and share report drafts via email, while several lower income participants did not have regular access to email. The consequence was frustration and hard feelings on both sides. Skills and experience in writing similarly made it easier for professionals to have an impact on the content of reports. These class biases are important for all of the "new" technologies of movement mobilization. They are more acute for computer based technologies than for cell phone based technologies.

Summing up this hodge podge of observations and anecdotes, the conclusion I draw about sociological practice is that partial knowledge and miscommunication are endemic when people with different backgrounds and experiences try to work together. They are especially acute in movements where conscience constituents are trying to help beneficiary constituents, but also arise as conflicts within "universal" movements like peace or environmentalism or anti-globalization and as conflicts within the women's movement and the gay movement. Our goal as sociologists should be to try to help increase the communication among diverse groups within movements. Facilitating communication cannot be an ego-trip or a one-person show. You have to see yourself as just one small player in a much larger group.

At the same time, we need to be aware of our own class/race/gender/culture and how that influences the knowledge we have and our capacity to communicate with others. Every ongoing mixedrace or mixed-class group that I have been in has experienced conflict and hard feelings over these divisions. Every ongoing mixed-race or mixed-class group I have been in has seen some people take offense at what others have said. I personally have managed to offend someone in every group I have ever been in. And I don't just mean offending opponents or powerful people, although I have done that, 
too. I have inadvertently offended less privileged people with my unconscious assumptions of superiority or my biased assumptions about them. Other times, I have been able to help back up a less privileged person who was trying to be heard or to facilitate communicating something a person wanted to say. There is no magic cure for the reality of these boundaries, there is only the willingness to notice them and try to build bridges and work around them.

\section{Academics as activist professionals}

There are many movements that are carried primarily by professional activists or activist professionals, and the movement to address racial disparities is one of them. There is no mass movement to empty the prisons nor a mass movement to change policing practices. Instead, there are professional reformers trying to get changes in the policies and practices of criminal justice systems around the country and another loose movement of reformers and service providers seeking more services for returning prisoners and the families of prisoners. Nationally, this issue is carried primarily by professional reformers in NGOs devoted to criminal justice issues or and Black social movement organizations. The major players in the criminal justice area tend to be small professional organizations that generate a lot of influential reports that they publish on the web. The activists in these organizations tend to have social science degrees. There is a growing niche of work involving analyzing data for social change and publishing reports and rankings on the web. These groups tend to be funded by progressive foundations. I have no first-hand knowledge of how national dynamics play out, but I have a lot of experience with local dynamics in Wisconsin, especially Madison.

Most of the activists in this loose movement in my area are professionals of various types. Many have jobs in the criminal justice system as police, judges, prosecutors, public defenders, correctional workers, or social service system workers and are operating as reformers from within. Many are Black and many of the Black professionals have relatives who are in or have been in prison. There are also 
White reformers inside the system, including several judges who have played key roles. There are also non-reformers professionals who have been active, including the White former district attorney (now a judge) who was a very faithful participant in all the meetings but who politely stonewalled any attempt to monitor or create significant reform within his office, citing overwork, inadequate resources and/or the importance of his staff's autonomy. Other active participants have been professional activists in community organizations and the heads of small non-profit minority-serving social service agencies. Some of these are ex-offenders who are now employed in prisoner-reentry programs. The quasigovernmental advisory body to reduce racial disparities in the juvenile system has been meeting regularly since 2003. The Governor's Commission and the Task Force were temporary ad hoc groups that pulled together people who had ongoing involvement in the issues. Madison-area Urban Ministry has taken on prison issues in a major way and runs the largest one of the largest programs for prisoner reentry. Local groups with a race focus also have projects and programs related to criminal justice or prisoner reentry including the Urban League, the NAACP, Centro Hispano, and several Black churches, along with the local YWCA, a primarily-White group that focuses on racial issues. Another major player is an 80-year-old White nun who is a sociology and criminology professor at a local college who has spent her life working on social justice with an emphasis on women prisoners and who (because my university does not have a criminology program or a night school) has taught the majority of criminal justice professionals in the city. White leftists have come and gone around this issue over the years; mostly they leave town when they graduate or move on to other issues. The advocacy group I have participated in-Money, Education and Prisons - spun off from Madison-area Urban Ministry and initially was a mixed-race group that evolved over the years into overwhelming White due to a variety of racial conflicts, and is now largely defunct although a few of us still show up for meetings held every month or so. 
A lot of the people who are most concerned about racial disparity and working hardest to address the problem are inside the system including police, judges, prosecutors, social workers, and correctional workers as well as some elected officials and agency bureaucrats. Many of the most committed activist professionals around this issue are Black. Even though a large share of the Black and Hispanic participants had college degrees and were professionals in criminal justice or social service systems, the racial axis mattered. Partly this is because Black and Hispanic professionals have more close contact with low income Black and Hispanic people than most White professionals do, and were more likely to have relatives or friends who were offenders. Black and Hispanic people also took for granted that racial discrimination was real. Many of these are African Americans who are deeply and personally connected with the affected communities. There is a visceral response. "They are locking us all up!" was a common response from Black people who were first seeing my charts. One of the most moving experiences for me was touring the maximum security (formerly supermax) prison with a mixed race group of people associated with the Governor's Commission. At one point, one of the Black male politicians broke down and cried over the emotions raised seeing so many Black men sitting behind bars. The Black woman in our group said she was just angry, so angry she could hardly talk.

One person I have worked with a lot is a Black prosecutor who is both quite outspoken about the problem of racism and discrimination in the system and very concerned about young people who are just out of control and seem to have no norms or connections with society. I have heard many other Black professionals echo similar concerns. I was in a group discussion with her once when she was arguing that young people had to be taught not to argue or struggle with the police because assaulting an officer is a felony and a felony ruins your life. Someone else made the point that the kids struggle with police because they are being mistreated. She said, yes of course they are being mistreated. She recounted her first experience with the police, as a young teen, when her brothers were thrown to the ground by police just because they were walking down the street where a Black person had recently 
committed a crime and the police thought they were suspects. She said, "I know why they don't like the police. But it ruined their lives."

The African American professionals have a different kind of stake in the issue from the White professionals and conscience constituents. They are in for the long haul; they cannot give up on the issue and move on to something else. At the same time, they would like to keep their jobs and have orientations affected by their occupations. They also don't have the romantic and simplistic views of life on the streets that many privileged White activists have.The race and class dimensions get very complicated and multi-layered.

Madison's Black police chief co-chaired the state's racial disparity commissions and had done a great deal within his department to reduce disparities, including systematically collecting and analyzing traffic stop data to identify suspicious patterns. There have been cases of officers being sanctioned and reassigned for patterns of bias. But he is still a police officer. He defends his officers against outside criticism and he does not take positions or actions that would lead him to lose his job. There was an pretty egregious incident in which police officers used a taser on a Black high school student at school when he tried to run away from arrest; the officers had violated official protocol for school arrests by not going through the principal and reason for the arrest was actually a bench warrant for a failure to appear in court that had actually been issued in error, not any threatening behavior by the youth. The chief backed the officers, saying they had violated no rules. But then he issued stricter guidelines for the acceptable use of tasers.

Activist professionals almost always defended their institutions against direct attacks from others. I once watched an exchange in which a Black judge criticized a Black police chief for not being a strong enough advocate of reducing racial profiling in policing; the back and forth involved the police chief citing limits on the ability to constrain officers in the field. Fifteen minutes later, the tables were turned 
when the police chief said that judges should take responsibility for detecting and eliminating bias in the prosecution of cases in their courts, and the judge objected, citing the inappropriateness of judges sanctioning prosecutors. The school system representatives (White) who had been heard on previous occasions to express concern (in suitably muted ways) that some teachers were too likely to react punitively toward Black children, nevertheless reacted with indignation when someone complained about the school system in general as being problematic and contributing to disparities. And despite this public expression of indignation, the school system enacted several policies to reduce disparities by constraining teachers' choices, including mandating a common primary grade curriculum across all schools to minimize the disruptions to education from the frequent transfers experienced by poor children and a policy change that eliminated "insubordination" as a justified grounds for suspension, after data revealed that white children were more likely to be suspended for crimes while black children were more likely to be suspended for insubordination.

The general point is that activist professionals always exhibited somewhat contradictory impulses. Activist professionals were usually deeply and genuinely committed to reducing disparities, but they were also committed to advancing their own careers, or at least to no hurting them. They were careful and circumspect about any criticism of their superiors, coworkers, or their agencies in general.

They had the most grounded knowledge about how to address problems within their own systems, tended to focus their attention on their own areas of expertise, and tended to be defensive and selfprotective about attacks on the institution from outside. Everybody from every institution knew that bad actors within their institution were the source of much of the problem, but the one thing people were not willing to do was absorb the political cost of challenging fellow employees to bring them into line. The only exception that I knew of was the police chief, who worked to institute a series of monitoring programs. He did reassign an officer after the officer kept on disproportionately stopping 
Latinos, but he did not fire him and he defended officers who were challenged by outsiders for their actions.

Another huge issue in my community, and I imagine others, is the allocation of jobs in the human services sector. Much social service work is not provided by government employees but is contracted out to nonprofit organizations. As a cost-saving measure, the county allocates most of these contracts to a few large White-dominated agencies such as Lutheran Social Services. A major grievance among Black professionals is that the people needing services are disproportionately Black, but the service providers are disproportionately White. This was one of the major issues that led to the early racial split in MEP, as Black activists felt this should be a focus of effort and Whites did not. It is not politically legitimate to pose this issue as one of who should get the jobs, so it is instead posed as the matter of providing "culturally appropriate" services. White service providers feel they can address cultural appropriateness by training White people in cultural differences, while Blacks and other minorities feel that you have to be in a culture to enact it and that their own bodily selves being in positions of authority is part of what makes something culturally appropriate. Because of its sensitivity, this issue is rarely discussed in crass job allocation terms, but it undergirds much of the latent conflict in some circles. There are also conflicts and competition within minority communities about leadership, ideology, and the allocation of scarce resources.

It seems to me that academics studying or working with movements they support should be understood similarly as activist professionals who both care about the movement and have individual interests with respect to it. Like any other professional, academics have to worry about not losing their jobs, especially if they do not have tenure. In addition, if they are trying to get professional publications out of what they are doing with the movement, they run into the problem of conflicts of interest. The things a person does to publish articles and build a professional career are not necessarily the best 
things to do if the goal is solely to build the movement. And if you need to get publications out of your activism, there is the danger that you may distort your actions or your perceptions of the best strategies to be consistent with your professional needs. There is also, of course, the tendency to think the movement really needs most what you want to give it. I, for example, remain convinced that diagnostic statistics are the most important thing to do for monitoring the performance of systems. I get pretty frustrated with activists (usually Black) who say "we don't need any more data, we already know we have a problem." I think we need data to tell use exactly where the problem is and to monitor whether what we have done has made it better. It's a delicate balance. I backed off on pushing data issues in the task force for a while because activists close to the problem said "we don't need any more data." Later when I explained about monitoring, they said: "Why didn't you say so?" Prosecutors and law enforcement don't want any more data-gathering requirements unless they get more funding because otherwise they see them as unfunded mandates that would further stress their already-restricted budgets. I was trying to argue that a well-designed data system could both permit monitoring and increase the efficiency of their operations and suggested strategies for inter-organizational cooperation to make it happen, but I could not win enough allies to my cause and had to give up.

Over the years I have been working on these issues, I have come to have more and more respect for people in the system. You need to have a broad view and a critical perspective that the academic view point gives you, but at the same time the broad view is often completely oblivious to what is actually happening on the ground. Just as state legislators can enact laws about driving privileges that seem reasonable to them but have devastating consequences for low income people, especially low income Black people, academics too can form wrong ideas about causal processes if they are too far removed from the problem. It is a lot easier to provide a social critique and evidence of a problem than it is find effective ways to pursue justice and undo the damage of past policies in the face of adverse political and economic constraints. It can be very frustrating and often boring to sit through long hours of meetings 
as people try to develop change plans and persuade others to adopt them. Building relations and becoming embedded in groups trying to find solutions broadens understanding but it takes a lot of time, time that you are not spending writing, publishing and advancing your career. 